\title{
On Embracing the Research Conference ${ }^{*}$
}

\begin{abstract}
Alyson M. Drake*
Research conferences belong in every research instructor's arsenal. In addition to having multiple pedagogical benefits, legal research conferences help students prepare for practice and comprehend that analysis is a critical part of legal research. And for instructors, conferences serve as a time to engage actively in the learning process and to receive feedback.
\end{abstract}

Introduction $\ldots \ldots \ldots \ldots \ldots \ldots \ldots \ldots \ldots \ldots \ldots \ldots \ldots \ldots \ldots$

Pedagogical Benefits of Conferencing with Law Students. . . . . . . . . 8

Students Receive Individualized Feedback $\ldots \ldots \ldots \ldots \ldots \ldots \ldots \ldots \ldots$

Students Practice Self-Direction and Self-Assessment $\ldots \ldots \ldots \ldots \ldots \ldots \ldots 11$

Instructors Better Understand How Students Learn . . . . . . . . . . . 12

Learning Styles Are Used to Best Advantage . . . . . . . . . . . . . 13

Collaborative Style Appeals to Millennial Learners. . . . . . . . . . . . 14

Importance of Legal Research Conferences . . . . . . . . . . . . . . 15

The Analytical Process Is Centered in the Research Stage . . . . . . . . . 15

Preparing for Practice. . . . . . . . . . . . . . . . . . . . . . . 18

How to Structure Research Conferences . . . . . . . . . . . . . . . . . . . . 19

Timing in the Semester . . . . . . . . . . . . . . . . . . . 19

First-Year Skills Courses . . . . . . . . . . . . . . . . . . . . . 19

Upper-Level Research Courses. . . . . . . . . . . . . . . . 20

Setting the Agenda and Tone. . . . . . . . . . . . . . . . . . . 21

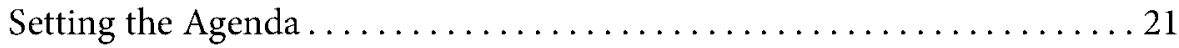

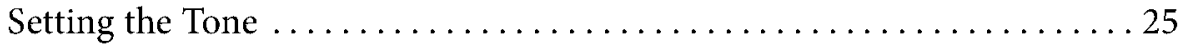

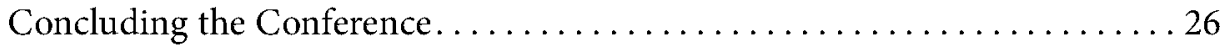

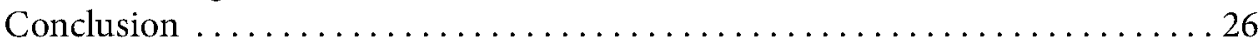

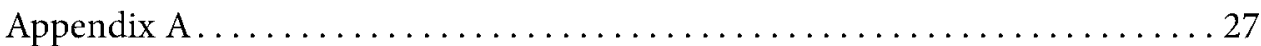

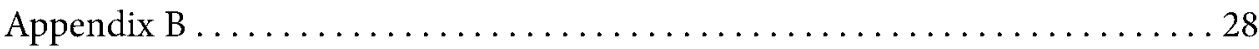

\section{Introduction}

I1 Analytical thinking begins during the research phase of the writing process. After all, students cannot-or at least should not-write until they have found

* (C) Alyson M. Drake, 2019. Many thanks to Jennifer Mart-Rice and Franklin Runge for reviewing drafts of this article and offering valuable feedback. I am also thankful to Desiree Hemphill for her excellent research assistance. This work was made possible by the support of the Texas Tech University School of Law.

** Assistant Director for Public Services, Director of the Excellence in Legal Research Program, and Adjunct Professor, Texas Tech University School of Law. 
appropriate authorities on their issues, and they cannot find appropriate authorities without significant analysis and organization of the issues before them. Furthermore, they cannot conclude their research without critical thinking about whether they have identified all of the underlying issues and found authorities that both answer all the questions that have arisen and allow for effective comparison with their own client's facts. In fact, many students struggle with the research process for just these reasons. As novice legal thinkers, the research process can be a significant barrier. Others simply do not engage in much analysis at all, viewing research as a task to gather sources that seem helpful, without giving enough thought to how they will use the sources they find. This results in their doing a poor initial analysis and then having to engage in a second round of analysis when it is time to write, which necessitates rereading all the sources.

I2 Individual student conferencing is a typical part of the law school experience, particularly in first-year skills courses where most students meet with their instructors several times during the academic year. Most often, these first-year meetings focus on the legal writing process as students work to produce their first closed and open memos and appellate briefs. While legal writing conferences are undoubtedly a critical part of law students' learning, an oft-forgotten component of these meetings is a discussion of the research component inherent in those writing assignments. In legal writing conferences, discussion of the authorities is generally limited to how to use the authorities the students have already located, at which point the students have already struggled immensely with their analysis. One solution for curbing the frustrations many students feel during this process is for instructors to hold one-on-one research conferences with each student prior to writing. In these meetings, instructors can help students with the analytical component of the research process as well as practical skills like locating authorities in an efficient manner and organizing their research in a way that facilitates moving from the research phase to the writing phase.

\3 Part 1 of this article discusses the benefits conferencing has for both students and instructors. Part 2 argues that legal research conferences are a critical component of law students' skills education, both to prepare them to engage in legal analysis and to ready them for practice. Finally, Part 3 discusses the practical considerations of introducing legal research conferences into the curriculum.

\section{Pedagogical Benefits of Conferencing with Law Students}

\section{Students Receive Individualized Feedback}

I4 Individualized feedback is rarely given in the traditional law school setting of a large lecture hall and the traditional grading schema of a single exam at the end of the semester. ${ }^{1}$ However, as the emphasis on lawyering skills continues to increase and experiential learning hours gain greater traction in the legal curriculum, ${ }^{2}$ individualized feedback will become even more important. In fact, ABA Standard 304 on simulation courses requires "opportunities for performance [and] feedback

1. Kristin B. Gerdy, Teacher, Coach, Cheerleader, and Judge: Promoting Learning Through Learner-Centered Assessment, 94 Law Libr. J. 59, 78, 2002 Law Libr. J. 4, I 69.

2. See generally Alyson M. Drake, The Need for Experiential Legal Research Education, 108 LAW Libr. J. 511, 2016 LAW Libr. J. 26. 
from a faculty member." ${ }^{3}$ The Standard also calls for "direct supervision of a student's performance." ${ }^{4}$ As conferences often take place in skills-focused courses qualifying as simulations, the instructor's direct supervision and feedback is more than just ideal for student learning; it is required under the Standards. ${ }^{5}$ Direct supervision is most easily achieved by one-on-one interactions between the instructor and the student. ${ }^{6}$

I5 Even when the ABA Standards do not require individualized feedback, there are numerous pedagogical reasons to provide it. Perhaps the largest benefit of holding research conferences is the near guarantee that a student will hear the one-onone, face-to-face feedback given. According to DeSanctis and Murray, most learning takes place via an "extended give-and-take process: the student-[researcher] executes an assignment, and the [instructor] reviews the work product and provides extensive commentary on what worked well and what could be improved going forward." While this evaluation of a student's work can come in the form of written feedback, students benefit more from the chance to talk about their research in a one-on-one atmosphere, where they can ask questions about their instructor's commentary. ${ }^{8}$ Conferences give students and faculty the opportunity to discuss large-scale issues in detail and break them down, a much less cumbersome task than a student trying to sort through pages of detailed written feedback.

I6 An in-person meeting between student and instructor forces the student to reflect on his or her performance in a way that simply skimming an instructor's comments cannot. For one, nothing guarantees that every student reads or fully understands the written comments. ${ }^{9}$ During an in-person meeting, the instructor and student are able to collaborate in moving the student forward in the learning process. This " $[c]$ areful, rigorous, guided and structured reflection on performance increases the learning of both skill and substance." ${ }^{10}$ An in-person meeting allows students to hear and absorb the feedback, as well as to ask questions related to it. ${ }^{11}$ Students are able to voice their concerns without having to schedule an appointment or stop by during office hours, which some students find intimidating. ${ }^{12}$

3. Am. Bar Ass'n, ABA Standards and Rules of Procedure for Approval of Law Schools 2015-2016, at 17 (2015) (Standard 304(a)(ii)) [hereinafter ABA STANDARDs].

4. ABA STANDARDS, supra note 3 (Standard 304(a)(i)).

5. See generally Drake, supra note 2.

6. See, e.g., Suzanne Rowe, Out of the Glass Cockpit: Teaching Legal Analysis in Legal Research, 20 J. Legal WRITING INST. 41, 44 (2015) ("A teacher with a group of even twenty students will be unable to monitor and refine twenty paths simultaneously.").

7. Christy DeSanctis \& Kristen Murray, The Art of the Writing Conference: Letting Students Set the Agenda Without Ceding Control, 17 Persp. 35, 35 (2008).

8. Id.

9. Elizabeth M. Bloom, A Law School Game Changer: (Trans)formative Feedback, 41 OнIо N.U. L. Rev. 227, 236 (2015) ("[S]tudents in the worst-case scenario are not even reading the feedback, and many of those who do read it are not able to understand it or use it to improve."); Robin S. WellfordSlocum, The Law School Student-Faculty Conference: Towards a Transformative Learning Experience, 45 S. Tex. L. Rev. 255, 268 (2004) ("[W]ritten comments are often confusing and susceptible to misinterpretation.").

10. Beryl Blaustone, Teaching Law Students to Self-Critique and to Develop Critical Clinical SelfAwareness in Performance, 13 Clinical L. Rev. 143, 153 (2006).

11. See DeSanctis \& Murray, supra note 7.

12. Kent D. Syverud, Taking Students Seriously: A Guide for New Law Teachers, 43 J. Legal Educ. 247, 253-54 (1993). 
I7 The variety of available research platforms and search strategies means there is no single "right way" to research a legal issue. But classroom instructors must appeal to the most common denominator. ${ }^{13}$ Teaching to the median can bore and thus lose students who have advanced beyond the average skill level. Alternatively, it can leave behind struggling students who most need instruction. ${ }^{14}$ But face-toface meetings allow students to receive individualized feedback about their specific issues and research strategies. Conferences are often students' most meaningful learning experiences, as they are keyed directly to what each individual student needs. ${ }^{15}$

I8 These conferences, then, fill another necessary goal of legal education under the ABA Standards-an opportunity for formative assessment and feedback. Under Standard 314, the ABA mandates that law schools "utilize both formative and summative assessment methods in its curriculum to measure and improve student learning and provide meaningful feedback to students." ${ }^{6}$ The ABA defines formative assessment methods as "measurements at different points during a particular course or at different points over the span of a student's education that provide meaningful feedback to improve student learning." ${ }^{17}$ Formative assessment gives students an opportunity to practice new skills and to make their "thinking visible to both teacher[] and student[]"18 Instructors cannot make visible each individual's thinking in a classroom setting because their attention is spread across the entire class. Conferences are an effective way to measure individual student improvement.

\9 Formative feedback is defined as "information communicated to the learner that is intended to modify his or her thinking or behavior for the purpose of improving learning." ${ }^{19}$ Effective feedback engages students and helps them to learn to self-assess their work, ultimately building self-confidence. ${ }^{20}$ Studies show that

[a]dults are usually highly motivated to learn and are willing to engage in participatory learning methods such as discussion, simulation, and small group activities. However, adult learners quickly withdraw their participation if they feel that the education is not meeting their needs, does not connect with their past experiences, or is conducted at a level they find incomprehensive. ${ }^{21}$

Conferences thus allow instructors to meet students where they are and students to connect their learning to their individual life experiences.

13. See DeSanctis \& Murray, supra note 7, at 36; see also Wellford-Slocum, supra note 9, at 265 (" $[\mathrm{T}]$ he learning that takes place in the classroom is, of necessity, general, [so] that forum cannot adequately address the myriad of thinking ... problems students face ....").

14. See DeSanctis \& Murray, supra note 7, at 36 (explaining that group settings force instructors to teach to the median skill level).

15. See Wellford-Slocum, supra note 9, at 266 (noting that conferences "allow[] the professor to focus on the specific needs of individual students and to work with each student from that student's unique reference point and stage of cognitive development").

16. ABA STANDARDS, supra note 3 , at 23 (Standard 314).

17. Id. (Interpretation 314-1).

18. Herbert N. Ramy, Moving Students from Hearing and Forgetting to Doing and Understanding: A Manual for Assessment in Law School, 41 CAP. U. L. Rev. 837, 844 (2013).

19. Valerie J. Shute, Focus on Formative Feedback, 78 Rev. Educ. Res. 153, 154 (2008).

20. Bloom, supra note 9 , at 234.

21. Gerald F. Hess, Listening to Our Students: Obstructing and Enhancing Learning in Law School, 31 U.S.F. L. Rev. 941, 942 (1997). 


\section{Students Practice Self-Direction and Self-Assessment}

110 Individual conversations between instructors and students can result in much greater understanding and motivation on the part of students. ${ }^{22}$ Studies show that when students take responsibility for their own learning and become skilled at self-critique, they are more likely to succeed in law school. ${ }^{23}$ This happens most readily when formative assessment and self-critique opportunities are inserted into the curriculum.

I11 Research conferences can help meet both of these goals. By having students fill out questionnaires identifying what they think they have done well and what they have struggled with ahead of the conference, ${ }^{24}$ they have the opportunity to self-assess and then compare their assessment with the instructor's while engaging in dialogue during the conference. Not only does this allow students to learn to critically assess their skills, but it requires them to become active members in their learning process. ${ }^{25}$ Conversing about assignments and research problems, then, stimulates independent learning and deepens understanding of legal issues. ${ }^{26}$ By considering certain questions, such as what they are struggling with, rather than just walking through the assignment to identify specific errors, students can learn how to answer their own questions. ${ }^{27}$

I12 One-on-one dialogues become especially important for students who are either above or below the class's median skill level. In a class setting, instructors must rely on identifying general problems that need addressing, but one-on-one conferences allow instructors to focus on the specific problems students are having and to suggest strategies to address those exact issues. ${ }^{28}$ Conferences also afford students the opportunity to explain their intentions, giving the instructor a clearer view into how they think. ${ }^{29}$ This, in turn, allows the instructor to suggest strategies tailored to each student.

I13 Furthermore, for many students, verbalization and discussion are the best avenues to clear thinking. Talking through legal rules and their thought processes with someone better versed in legal analysis helps them to better understand the legal issues. ${ }^{30}$ Active learning, including discussion, helps students to develop higher-level thinking. ${ }^{31}$ Discussing the legal issues involved in an assignment helps students feel as though they are collaborating alongside the instructor in their learning process. $^{32}$

22. Arthur W. Chickering \& Zelda F. Gamson, Seven Principles for Good Practice in Undergraduate Education, 17 BIOCHEM. EDUc. 140 (1989) ("Frequent faculty-student contact in and out of classes is the most important factor in student motivation and involvement. Faculty concern helps students get through rough times and keep on working.").

23. Bloom, supra note 9 , at 230.

24. See Appendix A, infra.

25. Bloom, supra note 9, at 243-44.

26. Gerald F. Hess, Value of Variety: An Organizing Principle to Enhance Teaching and Learning, 3 ELON L. REv. 65, 81 (2011).

27. DeSanctis \& Murray, supra note 7 , at 38 .

28. See $i d$. at 36 (noting that one-on-one writing conferences allow instructors to "tie instruction to the particular paper and focus on what to do next, suggesting strategies for the writer to use rather than merely identifying problems").

29. See id. at 37.

30. Id.

31. Hess, supra note 21 , at 943.

32. See id. (discussing the value of collaboration between student and instructor in the learning process). 
I14 In addition, one-on-one conferences can create a relationship between the instructor and student that leads to more engaged students. As Kent Syverud writes in his article Taking Students Seriously: "Your students will know whether you like and respect them, and if they know that you do not, you will fail as a teacher." ${ }^{3}$ Conferences help students and instructors to develop a mutual respect, as the instructor has more time to show that he or she values each student as an individual, which can be more difficult to do in a classroom setting. ${ }^{34}$ Conferences, when structured appropriately, ${ }^{35}$ also allow students to drive the interaction. When students feel valued and heard by their instructors, they are more likely to remain engaged in the learning process. ${ }^{36}$

\15 Finally, conferences give instructors time to check in with their students. Research and writing instructors, as some of the few instructors in the law school giving regular assignments throughout the semester, are better situated to monitor their students' well-being and academic success. In conferences, instructors can check in with their students one-on-one, in an atmosphere where students are less likely to be self-conscious. Upon finding or being told directly by a student that he or she is struggling, either with research and writing or with law school work in general, instructors can direct students to the appropriate law school department for additional help. Likewise, instructors can forward any concerns-or even accompany a student directly-to campus mental health resources.

\section{Instructors Better Understand How Students Learn}

I16 Without question, one-on-one conferences can be time consuming for instructors, as they must first familiarize themselves with students' strengths and weaknesses and then actually meet with students. ${ }^{37}$ But conferences allow instructors to more actively engage in the learning process and to receive feedback. ${ }^{38}$ By meeting with students individually, instructors better understand how the students in their classes learn. ${ }^{39}$ It also provides instructors with important intelligence on what is and is not working well in the classroom and allows them to "make adjustments during the course to ensure students are learning the important content and skills." ${ }^{2}$ As such, conferences can help shape classroom dynamics and "maximize student learning." 41

\17 Once meeting with all of his or her students, the instructor has a clearer picture of global issues with which the class is struggling. These issues can then be shared with the entire class. This allows students who had more significant issues in different areas and who may not have had a chance to discuss these global issues in their individual conferences to benefit from the classroom discussion. ${ }^{42}$

33. Syverud, supra note 12, at 247.

34. Hess, supra note 21 , at 942.

35. See infra, pp. 21-25.

36. See Syverud, supra note 12, at 254.

37. DeSanctis \& Murray, supra note 7 , at 35.

38. Gerdy, supra note 1, at 65, I 25 ("Effective, learner-centered assessment enables teachers to answer two key questions: What have my students learned and how well have they learned it? How successful have I been at accomplishing the goals and objective I have set ... ?").

39. Hess, supra note 26 , at 87 .

40. Id.

41. Id. at 90 .

42. DeSanctis \& Murray, supra note 7, at 37. 
I18 Finally, conferences allow the instructor to get to know students better as human beings. As students become more comfortable with the instructor, they are more willing to ask questions inside and outside of the classroom, which can result in increased learning. ${ }^{43}$ If students feel that their learning is important to the instructor, they are also more likely to become self-motivated to continue engaging in the learning process. ${ }^{44}$

\section{Learning Styles Are Used to Best Advantage}

\19 Unlike the traditional lecture format that most law school instructors employ, research conferences can be adapted to appeal to all learning styles. Learning styles are defined as "the way in which individuals 'begin[] to concentrate on, process, [internalize,] and remember new and difficult [academic] information' or skills." ${ }^{\prime 5}$ Studies have shown that college students perform at higher levels when the instructional method used aligns with their individual learning styles. ${ }^{46}$ In testing law students for learning styles, researchers found that law students fit into each of the different learning styles. ${ }^{47}$ Most law students have primary, secondary, and even tertiary strengths, meaning that they use various learning styles when absorbing new materials. ${ }^{48}$ As such, teaching solely by lecture and written practice exercises is unlikely to fully engage all students.

I20 Students who learn best via auditory methods, approximately 26 percent of law students in a study by Boyle \& Dunn in the late 1990s, remember approximately three-quarters of a 50 -minute lecture. ${ }^{49}$ Just as these students remember much of what they hear in a traditional lecture ${ }^{50}$ they will recall much of the discussion in a research conference focusing directly on their individual strengths and weaknesses. Conversely, those with low auditory strengths struggle greatly to learn through listening and need teaching methods that differ from the traditional law school lecture.

I21 Students with high visual strengths, 8 percent in the Boyle \& Dunn study, remember what they read or what they see. ${ }^{51}$ For these students, a visual component is critical to their learning. ${ }^{52}$ Tools such as a research log work well for most visual learners, probably more so than lectures or research exercises. The visual device helps them to more easily see the patterns that evolve. Instructors can draw or use images or flowcharts for students during conferences to help them better understand how to organize their research and as aids in their analysis. ${ }^{53}$

43. See Syverud, supra note 12, at 254 .

44. See id.

45. Robin A. Boyle \& Rita Dunn, Teaching Law Students Through Individual Learning Styles, 62 Alb. L. Rev. 213, 214 (1998) (quoting Rita Dunn \& Kenneth Dunn, Teaching Secondary Students Through Their Individual Learning Styles 2 (1993)).

46. Id. at 215 .

47. Id. at 224.

48. Id. at 226 (recommending a certain sequence for ideal learning: (1) introducing the material using a student's primary strength; (2) reinforcing the material using a secondary or tertiary strength; and (3) having students utilize "the newly acquired knowledge in a creative way to ensure application of knowledge").

49. Id. at $227-28$.

50. Id. at 228 .

51. Id.

52. Id. at $228-29$.

53. One way to do this is for professors to demonstrate to students how to draw a spectrum for a legal issue. For example, say that the student is researching whether an unoccupied RV counts as a 
I22 Students with high tactual strength, 21 percent of law students, learn best by using their fine motor skills-often through writing, drawing, or doodling. ${ }^{54}$ Research instructors would do well to provide students with a copy of their draft research during conferences, so students can manipulate their research organization by taking notes on the page. Students might best be able to explain their thought process by charting or graphing, and research instructors can allow for that flexibility when conferencing with these students in a way they may not be able to in the classroom. For these students especially, using a pre-conference questionnaire to self-evaluate their strengths and weaknesses can be a useful tool, ${ }^{55}$ as they can brainstorm on paper prior to the conference to get their minds engaged.

I23 Finally, students who are kinesthetic learners, 16 percent, remember best by doing. ${ }^{56}$ One helpful way to reach these students is role-playing. ${ }^{57}$ In research conferences, the student might play the part of the junior partner and relay his or her research findings to the senior partner. Kinesthetic learners should bring their laptops to the conference so instructors can explain the ideal research methodology while the students walk through a relevant database themselves to reinforce learning. These students also sometimes learn best while moving, ${ }^{58}$ so the option of a "walk-and-talk" research conference might also be beneficial.

I24 Many students have strengths in two or even three areas, ${ }^{59}$ so incorporating learning tools directed at a diversity of methods is the most likely way to guarantee student learning. This is especially true in initial meetings, in which the instructor does not know the student's learning preferences yet. After getting to know students better, instructors can tailor conferences more directly to students' preferred learning types. Research conferences, as a tool that can appeal to all four learning types, are a helpful teaching strategy to introduce into one's arsenal to ensure student learning. They can more easily be adapted to students' individual learning strengths than the classroom setting and result in greater comprehension for each student.

\section{Collaborative Style Appeals to Millennial Learners}

I25 In addition to benefiting different types of learners, research conferences are likely to appeal to the average Millennial learner, the generational group into which most current law students fit. Millennials tend to share a number of learning and societal characteristics. ${ }^{60} \mathrm{~A}$ few of these characteristics are particularly well matched to the personalized, more flexible environment provided in research conferences.

habitation in the burglary context. No cases in their jurisdiction directly answer that question. They should see how other non-houses have been treated by courts. Professors can draw a spectrum and have students place how those other non-houses have been treated-as habitations or as not being habitations - and then have students determine where the unoccupied RV might fit among those authorities by comparing and contrasting facts and the courts' reasoning.

54. Boyle \& Dunn, supra note 45, at 229.

55. See Appendix A, infra.

56. Boyle \& Dunn, supra note 45 , at 231.

57. Id. at $231-32$.

58. Id.

59. Id. at 244 .

60. See, e.g., Emily A. Benfer \& Colleen F. Shanahan, Educating the Invincibles: Strategies for Teaching the Millennial Generation in Law School, 20 CuInICAL L. Rev. 1, 8-14 (2013) (enumerating the specific characteristics of the Millennial learner); Aliza B. Kaplan \& Kathleen Darvil, Think [and Practice] Like a Lawyer: Legal Research for the New Millennials, 8 Legal Comm. \& Rhetoric 153, 154 (2011) (describing Millennials as "special, sheltered, confident, team-oriented, conventional, 
I26 Millennials are used to teamwork and collaborative educational techniques, ${ }^{61}$ having grown up in classrooms using peer-learning techniques. They are not only comfortable with this collaborative education but have come to "expect a collaborative learning environment." 62 They are eager for and may even expect teacher-student collaborative opportunities, being used to a "co-partnership' with supervisors and teachers." ${ }^{3}$ In fact, due to this upbringing, Millennials may be somewhat uncomfortable engaging in autonomous thinking. ${ }^{64}$ Because of this lack of confidence in working independently, research conferences become even more important, as they are an opportunity for students to still work collaboratively and keep the sense of connectedness they crave, while being guided by the instructor to be more self-sufficient thinkers.

I27 Millennials are also used to personalized educational experiences, ${ }^{65}$ in which they are guided through the educational process and "assisted often when the task required independent, creative thinking and decision-making skills." ${ }^{6}$ However, Millennials crave the chance to work alongside veteran colleagues, want to be treated as partners in their learning process, and desire to be included in their own goal setting. ${ }^{67}$ Research conferences give them a chance to partner with more experienced professionals and to be active in their own learning experiences while forcing them to engage in the analytical processes with which they may be less familiar. Research conferences recognize and fulfill the Millennial law student's need for collaborative, personalized learning, while helping them overcome their generation's trademark struggle to engage in independent thinking by allowing them to practice such thinking directly under the guidance of their instructors.

\section{Importance of Legal Research Conferences}

\section{The Analytical Process Is Centered in the Research Stage}

I28 A common misconception has it that research is largely a mechanical function rather than an analytical exercise. ${ }^{68}$ As Barbara Glesner Fines aptly notes,

pressured, and achieving"); Brittany Stringfellow Otey, Millennials, Technology, and Professional Responsibility: Training a New Generation in Technological Professionalism, 37 J. Legal Prof. 199, 206-13 (2013) (listing Millennial characteristics).

61. See Susan Azyndar, Work with Me Here: Collaborative Learning in the Legal Research Classroom, 1 LEGAL INFO. REv. 1, 3 (2015-2016) ("[T]his group experienced collaborative learning extensively in prior schooling, comfortably adopts this educational strategy, and even much prefers this kind of learning environment.").

62. Benfer \& Shanahan, supra note 60 , at 11.

63. Id.

64. Otey, supra note 60, at 207.

65. Kari Mercer Dalton, Bridging the Digital Divide and Guiding the Millennial Generation's Research and Analysis, 18 BARRY L. REv. 167, 171 (2012) ("Millennials have come to expect products and services to have as many 'personalization and customization features as possible' to accommodate an ever-evolving series of demands, interests, and preferences.").

66. Benfer \& Shanahan, supra note 60 , at 12.

67. Id. at 13 ("They expect to work with supervisors who treat them as equals rather than with supervisors who act in an authoritarian manner or enforce a hierarchical structure.").

68. See Paul D. Callister, Thinking Like a Research Expert: Schemata for Teaching Complex Problem Solving Skills, 28 Legal Reference Servs. Q. 31, 48 (2009) (noting that faculty members have deprioritized legal research because it lacks "critical reasoning"); Genevieve Blake Tung, Academic Law Libraries and the Crisis in Legal Education, 105 LAW LiBr. J. 275, 286, 2013 LAW LiBR. J. 14, II 23 
The conflation of research instruction with bibliographic instruction has hindered the development of research pedagogy even within the community of experts. To truly improve legal research instruction, the pedagogy must be developed to recognize the analytic and creative aspects of the research process as research, rather than thinking of research instruction as nothing more than mastering a set of finding tools. ${ }^{69}$

I29 In reality, research is a highly analytical task. ${ }^{70}$ As such, it is a mistake to hold off on student conferences until the writing stage of an assignment, bypassing the part of the process that for many students is the most frustrating. ${ }^{71}$ By the time students begin writing a memo or appellate brief in their first-year classes, they should have already spent hours engaged in complex issues of legal analysis. ${ }^{72}$

\30 Legal educators have noted for decades that legal research is "more than a mechanical examination of texts." ${ }^{\prime 3}$ The MacCrate Report states that "the formulation and implementation of a research design are analyzed as processes which require a number of complex conceptual skills." ${ }^{24}$ This stems from the fact that research is largely a problem-solving endeavor, which by its very nature is analytical. ${ }^{75}$ From the moment a student or attorney is presented with a factual scenario, he or she must consider what the problem is and a strategy to answer it effectively and efficiently. ${ }^{76}$ As students develop a research plan, they must consider what the broad-scale issues are and what resources they should look at first to begin answering their questions. ${ }^{77}$ As students begin to locate authorities, they must constantly evaluate whether and how those sources are relevant to their identified issues. ${ }^{78}$ Eventually, students must use synthesis to determine whether the authorities they have identified fully answer their problem. ${ }^{79}$ As Sarah Valentine notes, " $[t]$ he process of legal research cannot be mechanically divorced from legal analysis and reasoning." 80

("Too often, though, legal research is assumed to be something straightforward and nonintellectual that can be easily mastered by new law students . . . "); Sarah Valentine, Legal Research as a Fundamental Skill: A Lifeboat for Students and Law Schools, 39 U. BALT. L. Rev. 173, 198 (2010) ("Legal research is generally compartmentalized within the legal academy as an easily learned, routine, and repetitive activity unconnected to legal analysis ....").

69. Barbara Glesner Fines, Out of the Shadows: What Legal Research Instruction Reveals About Incorporating Skills Throughout the Curriculum, 2013 J. DisP. Resol. 159, 186.

70. Id.; see also Rowe, supra note 6, at 42 (" $[\mathrm{R}]$ esearch is an analytical process, not an automatic system of document retrieval.").

71. Valentine, supra note 68 , at 179 (noting that students can be "overwhelmed by the ocean of information they must manage, search within, and understand").

72. Fines, supra note 69 , at 186 ("[E]xpert legal research involves the same kind of issue identification and analysis as is the standard fare of a law school exam bluebook.").

73. A.B.A. Task Force on Law Sch. \& The Profession, Legal Education \& Professional Development-An Educational Continuum 163 (1992) [hereinafter MacCrate Report].

74. Id.

75. See Valentine, supra note 68 , at 200 (noting that legal research involves "creative problemsolving").

76. Id. at 207.

77. Id. at 210 . It would be impossible to do legal research without analyzing, synthesizing, and applying the information found, both to the original issue and to the research plan developed to address the issue. The process of legal research requires an ability to determine legal context, assess the law found in the process, and understand how what is found relates to specific situations. Id. at $210-11$.

78. Ian Gallacher, Forty-Two: The Hitchhiker's Guide to Teaching Legal Research to the Google Generation, 39 Akron L. Rev. 151, 158 (2006).

79. Valentine, supra note 68 , at 201.

80. Id. at 211 (emphasis added). 
\31 Like the MacCrate Report, the American Association of Law Libraries' Principles and Standards for Legal Research Competency makes it clear that legal research requires analysis. ${ }^{81}$ Two of the standards are explicit about this need: Principle III, "A successful legal researcher critically evaluates information," includes skills such as judging reliability, fine-tuning research questions, and finding and evaluating contradictory authority. ${ }^{82}$ Principle IV, "A successful legal researcher applies information effectively to resolve a specific issue or need," includes synthesizing research problems, identifying unresolved issues, "incorporat[ing] analogous background as appropriate if research has not clearly resolved all ambiguities or uncertainties within the issue posed," and assessing the effectiveness of prior strategies. ${ }^{83}$

I32 Even the principles that seem to have less to do with analysis include analytical tasks. For example, Principle I, "A successful legal researcher possesses foundational knowledge of the legal system and legal information sources," includes the ability to select appropriate and effective sources. ${ }^{84}$ Principle II, "A successful legal researcher gathers information through effective and efficient research strategies," includes "[analyzing] research results using prior knowledge and experience on the topic in particular, as well as one's general knowledge of legal principles" and "[developing] an appropriate research plan for each discrete issue." 85 As such, waiting to hold a conference until after the student has already struggled through the critical analysis integral in the research process makes little sense. First, this sends the faulty message that research is a mechanical task. Second, it wastes students' time, as they engage in the analysis intrinsic to research while gathering sources and then repeat their analytical work-usually by rereading all their sources-when it is time to write.

\33 Given how enmeshed analysis is with the research process, meeting with students during the research phase when they are deeply entrenched in analysis is a better pedagogical tool. Students will be able to verbalize what key issues they have identified, how and why they are relying on particular authorities, and how these authorities are answering those issues before getting bogged down in the equally difficult task of expressing their findings in writing. A research conference will allow them to reason out their analyses before they put pen to paper. ${ }^{86}$ In fact, meeting during the research phase will likely produce better analyzed and written first drafts of memos and appellate briefs.

\34 Finally, meeting at this critical point in the process emphasizes the importance of legal research as a highly critical lawyering skill. In the legal curriculum, research has been relegated to the background. ${ }^{87}$ Bringing it to a place of prominence in students' educational experience is particularly important given that attor-

81. See Am. Ass'n of LaW Libraries, Principles \& STANdards for Legal ReSEARch Competency (2013), https://www.aallnet.org/advocacy/legal-research-competency/principles-and-standards-for -legal-research-competency/ [https://perma.cc/U8AN-SGNZ] [hereinafter PrINCIPLES \& STANDARDs].

82. Id. at $6-7$.

83. Id. at $7-8$.

84. Id. at 4 .

85. Id. at $5-6$.

86. This is not to say that students will not continue the analytical process while writing. As they write, they may come to find that there are lingering, unanswered questions that require further research.

87. Drake, supra note 2, at 529. 
neys are spending approximately a third of their time conducting legal research. ${ }^{88}$ Research conferences are one way to illustrate this to students.

\section{Preparing for Practice}

I35 Holding research conferences also helps prepare students for their lives as attorneys. The abilities to collaborate on and communicate about legal issues are key lawyering skills. ${ }^{89}$ Research conferences give students the chance to collaborate with another legal professional-their instructor-and to learn how to effectively discuss the authorities they have located and how they are relevant to the legal issues before them.

I36 As Susan Azyndar recently noted, "collaboration and teamwork have been recognized as pillars of the [legal] profession." 90 No attorney can succeed in his or her profession without collaborating with others: clients; supervising attorneys; colleagues within their practice group; judges; and nonlawyers related to the legal arena, such as police officers, psychologists, and the like. ${ }^{91}$ Collaboration is the result of "a group of knowledge workers integrat[ing] their individual expertise in order to deliver high-quality outcomes on complex issues, typically extending over time and across discrete projects as they identify new approaches and initiate further engagements." ${ }^{32}$ It allows individuals to be partners in the process, as they advise and engage one another. ${ }^{93}$

\37 Scholars have noted that Millennials' tendency to work in groups has hampered their ability to think independently. ${ }^{94}$ Research conferences, when structured appropriately, afford instructors the opportunity to help students cultivate the ability to think for themselves, to evaluate their own thought processes by asking questions, and to learn to talk about these issues in an organized and coherent manner. Conferences give students the chance to simulate talking to a fellow attorney or supervisor effectively and efficiently and to learn to self-critique their analytical processes. ${ }^{95}$ Finally, conferences enable instructors to positively model appropriate meeting behavior, such as being prepared and being collaborative. ${ }^{96}$ They also give students the opportunity to learn to listen, receive feedback, and resolve conflict. $^{97}$

$\llbracket 38$ While critics may argue that writing conferences afford students the same opportunity to collaborate, practice listening, and receive feedback, writing conferences rightly tend to focus a great deal on the mechanics and organization of the

88. Steven A. Lastres, Rebooting Legal Research in a Digital Age 1 (2012), https://www .lexisnexis.com/documents/pdf/20130806061418_large.pdf [https://perma.cc/BCF5-B4KA].

89. ABA STANDARDs, supra note 3 , at 16 (Standard 303(a)(3)).

90. Azyndar, supra note 61 , at 5.

91. Id. at 6, 8; John Lande, Reforming Legal Education to Prepare Law Students Optimally for Real-World Practice, 2013 J. Disp. Resol. 1, 14 (noting that studies of client satisfaction have found attorneys' communication skills to be lackluster).

92. Heidi K. Gardner, Effective Teamwork and Collaboration, in MANAGING Talent for Success: Talent Development in Law Firms 146 (Rebecca Normand-Hochman ed., 2013).

93. Id.

94. See supra note $63 \&$ accompanying text.

95. See Wellford-Slocum, supra note 9, at 311.

96. See id. at 292 (" $[\mathrm{B}]$ y building positive, encouraging, and collaborative relationships with students, the law professor models for students how to create such relationships later with their own clients.").

97. Azyndar, supra note 61 , at 9-10. 
writing, as this new style of writing is so foreign to students. Research conferences give students a chance to focus more on the authorities they have located and how those authorities are relevant to the issues they are investigating, without having to focus on the challenging tasks of communicating those issues in writing. Students must be able to learn to effectively discuss issues they are researching, and not just in writing.

I39 According to AALL's Task Force on Identifying Skills and Knowledge for Legal Practice, 35 percent of attorneys begin their research by seeking advice from another attorney. ${ }^{98}$ Another 29 percent do so occasionally. ${ }^{99}$ Likewise, other studies have shown that attorneys often draw on their colleagues' expertise. ${ }^{100}$ As such, it is critical that students develop the skill to speak intelligently about hierarchy of authorities and how specific authorities are relevant to the legal issues they are researching, as well as be able to discuss their analytical processes aloud. Students also need to learn to discuss their research strategies with colleagues, so that they can practice incorporating others' advice about their strategies, what sources to consult, and so on. While students could get a chance to practice this in class, a research conference simulates the one-on-one experience that happens in practice.

\section{How to Structure Research Conferences}

I40 An instructor could add research conferences to his or her syllabus in any number of ways. This section presents one option for incorporating research conferences into both first-year skills courses and upper-level research courses.

\section{Timing in the Semester \\ First-Year Skills Courses}

\41 Finding a place to add a research conference in an already packed first-year syllabus may seem challenging. But the benefits to students are more than worth the effort.

I42 In first-year skills courses, two conferences are recommended. The first is a conference held in the first week or two of school to simply get to know students. The goal of this set of conferences is to build a relationship that the instructor and student can use throughout the semester. This rapport building goes a long way in having subsequent successful conferences, of both the research and writing varieties.

I43 These conferences can be as short as 15 minutes and can take place in the instructor's office or a more casual setting, such as the law school's café or even outdoors. Colleagues at other law schools have held these initial meetings in small groups, but one-on-one meetings between individual students and the instructor allow them to have real conversations and ensure that one student's time is not monopolized by an over-eager classmate.

98. AlL-SiS Task Force on Identifying Skills and Knowledge for Legal Practice, A Study of Attorneys' Legal Research Practices and Opinions of New Associates' Research Skills 10 (June 2013), http://www.aallnet.org/sections/all/committees/practicetf/final-report-07102013.pdf [https://perma.cc/PZP9-EFHZ].

99. Id.

100. See Azyndar, supra note 61, at 13 (describing studies where attorneys look to their colleagues for advice). 
I44 The second conference is the substantive one. In this model, first-year skills instructors ideally will discuss the sources in the closed memo at length with students in class, asking them to unpack how each source would be applied to the client's facts before any discussion of writing begins. Including a few unhelpful sources in the closed memo packet will help students to better understand that not all sources that seem relevant are. A discussion of the level of analysis required in the research process at this juncture is critically important so students do not focus on writing as the focal point of the course. Then, the research conferences would be scheduled approximately a week after the open memo problem has been distributed to the students. This allows students a week to try to locate sources, analyze their usefulness, and organize their research in some fashion before meeting with their instructor.

\45 Holding conferences in place of one or more of the classes for this week will save the instructor time, as these conferences should be at least 30 minutes long, but this may be difficult with all the other material to be covered. However, after meeting with the instructor, students should have a much better handle on how to use the sources in their memos, likely producing a higher-quality writing product for their open memo drafts.

\section{Upper-Level Research Courses}

I46 With the focus of upper-level research courses being squarely on research, it is easier for the instructor to create a syllabus that incorporates multiple research conferences. A minimum of three conferences is recommended.

I47 The first conference, like in the first-year skills class, should be held in the first two weeks of class. Unlike the first-year skills class, this conference should serve a dual purpose. In addition to serving as a get-to-know-you conference, it should be combined with a short research exercise, such as developing a research plan or conducting background research on a client problem using secondary sources. The conference should be scheduled for 30 minutes, with the time split between relationship building and discovering where students are in terms of their research abilities at the start of the semester, since students often come into these classes with highly variable ability levels. ${ }^{101}$

I48 Scheduling the second and third conferences will depend in part on the structure of the course. If the course is a simulation with client problems, the conferences should be scheduled approximately a week after two of the client problems are introduced. This will give students time to conduct research before meeting. If the course is not a simulation and covers, for example, a different type of resource each class, consider combining a few of the resources for a larger problem so students will have the opportunity to undertake a problem more similar to what they would see in practice. Then, schedule conferences for the week after these assignments.

I49 Regardless of scheduling, these conferences should be scheduled for a minimum of 30 minutes. Why two conferences? They serve as a strong formative and individualized assessment tool for the instructor to ensure that the students are

101. See Gerdy, supra note 1, at 81 , I 80 (noting that teachers frequently need to "assess where the students are at the beginning of the course to determine what remedial work and review will be required"). 
moving forward throughout the course of the semester. The conferences will build on each other.

\section{Setting the Agenda and Tone Setting the Agenda}

I50 For both first-year skills courses and upper-level research courses, the instructor should set the agenda for the first conference. One way to formulate questions is to consider what would be helpful to know about students. ${ }^{102}$ There are two main fields of inquiry. First, learn something about each student. Where is the student from? Why did he or she come to law school? Are there areas of law that particularly interest the student? This line of questioning allows instructors to get to know their students, to make connections, and to have topics of conversation with them in subsequent meetings. ${ }^{103}$

T51 Second, an instructor should figure out each student's research background. Has he or she worked as a paralegal? Did the student clerk for a judge? What was the student's undergraduate major? The answers can help when discussing research with them later on and to get an idea of where their baseline skill levels might be.

I52 First conferences for an upper-level course should add a third level of inquiry: what are students hoping to get out of the course? Distributing a short preconference questionnaire is one way to stimulate the conversation. ${ }^{104}$ Questions that might be used on the questionnaire include:

- What are you hoping to get out of this course?

- What are your researching strengths?

- What are your researching weaknesses?

- What are three types of sources that you need to learn to use more effectively?

- If you were going to know how to perform one research skill at the end of this course that you don't know how to do now, what would it be?

- What area of law are you hoping to practice?

The instructor could also ask about students' comfort levels with particular types of resources. ${ }^{105}$

I53 Asking only the first question will result in fairly vague answers like wanting to be more efficient or faster. The second two questions will usually result in fairly vague answers, such as being proficient at Westlaw or Lexis or not being good enough at Boolean searching. The question asking about three types of sources they need to learn to use more effectively will require students to think more specifically

102. See, e.g., id. (recommending a questionnaire at the outset of a course asking, for instance, what are the student's short-term goals for the course and how this course might relate to their future).

103. See Wellford-Slocum, supra note 9, at 306 ("Open questions about the student's interests, professional goals and concerns give the student permission to talk freely and openly."). Rapportbuilding questions "also signal that the professor is interested in the student as a person." Id.

104. See Appendix B, infra.

105. See id.; see also Gerdy, supra note 1, at 81 , I 80 ("A more specific questionnaire can ask students to respond to subject-related queries in an attempt to check their knowledge before moving on to more advanced topics."). Gerdy notes that these questionnaires work particularly well for upperlevel research courses "where teachers must often assess where the students are at the beginning of the course to determine what remedial work and review will be required." Id. 
about what they have struggled with before. The final two questions allow the instructor to tailor research assignments to students' particular interests and goals for the course, which can increase each student's interest in completing the research problem. For example, if half the class is interested in criminal law, the instructor can make one of the client problems a criminal law matter.

154 The answers to these questions can stimulate fruitful conversation during the conferences. Even the first two questions are information about students' broad goals for the course. The answer "I want to be more efficient" can lead to a conversation about why that student feels like his or her research is not efficient right now. Beyond creating points for discussion in the conference, the questions can also help the instructor shape the syllabus to ensure that students get what they hoped out of the course by semester's end. Knowing students' expectations for the course also provides instructors with a helpful measure of each student's progress to check across the semester in conferences and written assignments.

I55 In the subsequent conferences, the instructor might try using a different questionnaire, which allows the student to effectively set the agenda for the conversation to take place. ${ }^{106}$ The questionnaire seen in Appendix A, which builds off of Blaustone's feedback model and Rodriguez's adaptation of that model into a written questionnaire, requires students to identify both the strengths and weaknesses of their research attempts, allowing them to gain important practice in self-critique. ${ }^{107}$ In addition, it results in students coming to the conference prepared to discuss specific questions and issues, which can help "promote self-sufficiency and independence." ${ }^{108}$ Instructors should explain the purpose of the questionnaire to students prior to their filling it out for the first time. ${ }^{109}$

\56 The first question requires the students to identify aspects of their research that they feel were done well. ${ }^{110}$ The questionnaire should instruct the student to be specific about what resources, methods, or analysis they feel they succeeded at using or doing. ${ }^{111}$

I57 As Blaustone notes in her feedback model, most students are unfamiliar with being asked to examine what they have done well, and may be vague. ${ }^{112}$ Blaustone strongly recommends giving students time to reflect in depth on what they have done well, rather than rushing into the negatives. ${ }^{113}$ Not only does this set a positive tone for the meeting, but it "reinforce[s] the premise that all performance

106. See Appendix A, infra.

107. The questionnaire I use in the second and third conferences in my course is based on the feedback model outlined in Blaustone, supra note 10, at 143-63. Blaustone's method is designed to provide feedback to students completing clinical tasks, but it is easily adapted to a questionnaire and format that is useful for research conferences with students. Sheila Rodriguez previously adapted steps one and four of Blaustone's method to a questionnaire for her legal writing students. Shelia Rodriguez, Using Feedback Theory to Help Novice Legal Writers Develop Expertise, 86 U. Det. Mercy L. Rev. 207, 223 (2009).

108. Wellford-Slocum, supra note 9, at 283.

109. Rodriguez, supra note 107 , at 224-25 ("If students do not understand why they are devoting time to filling out forms and evaluating their [work], they will be less inclined to provide meaningful commentary.").

110. See Appendix A, infra.

111. Id. Rodriguez also recommends including a note that students are not allowed to leave questions blank on the feedback form. Rodriguez, supra note 107, at 224.

112. Blaustone, supra note 10 , at 155.

113. Id. 
contains strengths as well as areas to target for further improvement." 114 By reflecting on their strengths prior to coming to the conference, students are engaging in self-critique, a critical lawyering skill. During the conference, the instructor can confirm whether the students' assessment of their work matches his or hers, helping students to improve their ability to assess their own work moving forward.

I58 The second question on the questionnaire asks the student to identify challenges he or she encountered during the research process and to recognize areas that require improvement or further research. ${ }^{115}$ Again, the student should strive to be specific about what resources, methods, or analysis they feel weak in using or doing. ${ }^{116}$ Filling out this part of the questionnaire also allows the student to practice assessing his or her work product and lets the student effectively set the agenda for what will be discussed during the conference time. ${ }^{117}$ It also allows those students who may be more introverted to get their thoughts together before having to converse with the instructor.

I59 Students should submit the questionnaires to the instructor at the same time that they submit their work product, or at least 24 hours prior to their conference, to give the instructor time to review. The instructor should make notes on the students' performance, marking specific examples of where each student struggled and succeeded prior to reading the students' questionnaires, so as not to be influenced or sidetracked by students' self-critiques. The instructor then needs to analyze the students' responses and see whether the students' identified strengths and challenges align with the instructor's perceptions.

I60 Once in the conference, it is the instructor's job to stick to the agenda set out by the student. Doing so strongly indicates to the student that his or her voice matters and that the instructor cares about the student's concerns. ${ }^{118}$ The conference should begin with the instructor providing positive reinforcement for those research strengths identified by the student. ${ }^{119}$ In the case that the instructor does not entirely agree with the student's purported strengths, he or she should still identify a point that showed the student's potential in that area. ${ }^{120}$ Then, the instructor can illustrate how the student could further improve. ${ }^{121}$ After discussing the strengths identified by the student, the instructor can point out additional areas where the student succeeded or showed potential for success. ${ }^{122}$ These should be "strengths that the student may have initially dismissed or undervalued." ${ }^{23}$ In the upper-level research course, if there are multiple research conferences, the instruc-

114. Id. at 156; see also Rodriguez, supra note 107, at 217 ("Positive feedback enhances perceived competence, which tends to increase intrinsic motivation.").

115. See Appendix A, infra.

116. See id.

117. See Wellford-Slocum, supra note 9, at 312 ("Explicitly encouraging students to share in the responsibility of evaluating their work also strengthens their intrinsic motivation to excel because students are thereby more inclined to internalize their role as the ultimate owner of the work product.").

118. Blaustone, supra note 10 , at 157.

119. See id.; see also Wellford-Slocum, supra note 9, at 323 (noting that cognitive psychology "suggest $[\mathrm{s}]$ that professors not simply discuss the weaknesses" in a student's work, but also recognize "where students have succeeded").

120. Blaustone, supra note 10, at 157.

121. Id.

122. Id.

123. Rodriguez, supra note 107, at 222. 
tor can also point out the student's improvements over the course of the class. This helps the student build self-confidence. ${ }^{124}$ Once the student sees how the instructor perceives his or her work positively, he or she is often better able to give a balanced self-critique next time. ${ }^{125}$

\61 After discussing the successes, it is time to turn to the challenges. Again, the instructor should begin by addressing those problems identified by the student, to show respect for the student's agenda. ${ }^{126}$ As Professor Wellford-Slocum notes in her article on writing conferences:

Some of a student's concerns are likely to overlap with the professor's own concerns .... Because students are more receptive to critiquing their own work when they have initiated the questions that inspire the critique, it is far more effective to discuss these issues in response to a student's question rather than forcing the student to defend his reasoning in response to the professor's critique. ${ }^{127}$

I62 If the instructor feels a point made by the student accurately identified a weakness, he or she should comment on how better to handle that situation the next time. ${ }^{128}$ Students are often too hard on themselves, so it is also an opportunity for the instructor to point out where students have handled something better than they thought. ${ }^{129}$ Finally, after addressing the student's concerns, the instructor should turn to those problem areas the student did not identify. ${ }^{130}$ This should be limited to major research and analysis issues that have not been touched on before or that were not discussed at length earlier in the discussion. ${ }^{131}$

I63 Blaustone notes that although this may be an uncomfortable part of the discussion for students, "any such feelings of unease will have been ameliorated in large part by the student's previously having taken ownership of the discussion."132

I64 The students and instructor should also discuss what further research needs to be done. Many students struggle with knowing when to stop researching, and this may be reflected in their responses on the questionnaire. The conference is a good opportunity for the instructor to reinforce that if (1) the student has answered all the questions set out in his or her research plan, and (2) the student is coming across the same sources repeatedly, he or she may stop. This emphasizes to students the importance of strategizing their research prior to jumping into the resources and helps them learn when to stop, a skill that normally only comes with experience.

\65 Finally, in the third conferences, an instructor requires students to simulate a scenario in which they report their findings to a senior partner. In these conferences, students should still complete the same preconference questionnaire. How-

124. Blaustone, supra note 10 , at 157 .

125. Id. at 158 .

126. Id.; see also Wellford-Slocum, supra note 9, at 313-14 ("If a student has a concern that is not being addressed because the professor elects first to pursue another line of inquiry, the student is less likely to be fully attentive to that dialogue.").

127. Wellford-Slocum, supra note 9, at 313.

128. See Blaustone, supra note 10, at 158.

129. Id.

130. Id. at 159.

131. Id.

132. Id; see also Rodriguez, supra note 107, at 217 ("Including positive components, such as praise and encouragement, in feedback helps to ameliorate the potentially ego-threatening effects of criticism and increases the likelihood that a student will accept the feedback."). 
ever, rather than diving immediately into what they have done well, students are able to practice discussing legal issues with a colleague. Because students have hopefully had a constructive conferencing experience with the instructor earlier in the semester, they are less nervous about presenting their research and discussing their analysis of issues. Once students report on their research, the instructor should turn to the preconference questionnaire to drive forward the agenda using the steps described above, but include feedback on, and discussion of, the students' oral communication skills.

\section{Setting the Tone}

I66 In setting the tone for the conferences it is important both to remember that the students are human beings and to show empathy for them as novice researchers. ${ }^{133}$ This means asking how they are doing and actually listening and then responding appropriately to that answer. Students can tell when their instructors are asking them a rote question and do not care about the answer. While it is important not to let their concerns-about law school, life, or whatever-overtake the purpose of the research conference, it is important to take a few minutes to converse with them. ${ }^{134}$ Not only does this show them that their instructor cares, but it sets them at ease for a conference that does require self- and instructor-critique, which is not the easiest task to undertake on a good day.

I67 After engaging in some small talk-or deeper talk, depending on the student-it is helpful to remind the student of the goals of this conference: his or her continued improvement as a researcher and a lawyer. It benefits students to be reminded that research is a skill that takes practice to improve upon. Reminding students that the discussion will be centered on their answers to the questionnaire will help them to feel like partners in the discussion before it begins.

I68 Continuing this positive tone during the dialogue between the student and instructor is also vitally important. ${ }^{135}$ Often this is conveyed through nonverbal communication, such as leaning toward the other participant to show interest, and smiling or nodding while holding eye contact to demonstrate collaboration and encouragement. ${ }^{136}$ Another important consideration is the seating arrangement. As one scholar notes, "[a] professor who faces students from behind a desk subtly reinforces the traditional hierarchy of control between student and law professor that is not conducive to building a collaborative working alliance." ${ }^{137}$ Sitting next to a student at a table may help the student feel more comfortable and better view the conference as a cooperative partnership.

133. See Syverud, supra note 12, at 250 ("[Y] ou should show, sometimes quite subtly, that you understand and are sympathetic to the problems that they are having even if you yourself are now an expert who no longer has these problems."); Wellford-Slocum, supra note 9, at 299 ("Empathy is the ability to enter another's world and somehow convey that we understand that world as if we were ourselves experiencing it." (emphasis in original)).

134. See Wellford-Slocum, supra note 9, at 298 ("The collaborative working alliance requires not just that the student and professor have a congruency of purpose, but also that the student experiences the professor as genuinely empathetic.").

135. Id. at 301.

136. Id. at 301-03.

137. Id. at 304 . 


\section{Concluding the Conference}

\69 It is important to end by reminding students of their strengths and, in the case of third conferences, to point out where they have improved over the semester. It is particularly helpful if the instructor can point out the student's improvement in the areas related to the student's purported goals for the course, as indicated on the first questionnaire.

I70 Instructors should consider ending the conference with goal setting. ${ }^{138}$ This not only ensures that students are comprehending the areas in which they need improvement, ${ }^{139}$ but it allows students to retain their sense of collaboration in the meeting. Have students jot down three goals for their next assignment and then go over these goals. If the student is missing one or more of the important points from the instructor's feedback, the instructor should suggest one more recommended goal, focusing on the most critical area in which the student needs to improve. The instructor should then photocopy this list of goals so he or she can review it prior to the next conference or assignment and be sure to address the student's goals the next time he or she is providing feedback, whether in conference discussions or in written comments on assignments.

\section{Conclusion}

171 Though time consuming, research conferences should be integrated into every research course. Not only do one-on-one interactions between students and instructors motivate student learning, but the individualized formative feedback allows each student to improve in the areas in which he or she is struggling. Research conferences also help prepare students for the practice of law, as they learn to communicate their research and analytical thinking orally and to self-critique their work.

I72 Conferences serve a second important purpose: they allow instructors to emphasize the importance of research in legal practice. Research conferences demonstrate to students that research is a highly analytical and often creative task, not just a rote task of gathering potentially helpful sources. This, in turn, teaches students not to procrastinate engaging in this analysis until they are staring down a writing deadline. Students will learn to engage with their analysis fully while researching-which should be one of every research instructor's goals for his or her students.

138. See id. at 346 ("In this phase of the conference, the student should summarize the important themes of the conference and his immediate goals following the conference.").

139. See Rodriguez, supra note 109 , at 222 (" $[B]$ efore concluding the conference, the teacher might resolve any uncertainty by confirming the student's overall understanding of the feedback."). 


\section{Appendix A}

\section{Texas Legal Research Preconference Questionnaire}

1. What do you feel went successfully during this research assignment? Please be specific about what resources you used well, what methods or strategies you used successfully, and where you feel your analysis was particularly strong.

2. What challenges did you encounter during this research assignment? Please be specific about what resources you had difficulty using, what methods or strategies didn't work as well, and any issues you had trouble resolving using the authorities you located.

3. Do you have any questions for me? 


\section{Appendix B}

\section{Texas Legal Research Preconference Questionnaire}

1. What are you hoping to get out of this course? Please be specific.

2. What are your researching strengths?
a.
b.
c.

3. What are your researching weaknesses?
a.
b.
c.

4. What are three types of sources that you need to learn to use more effectively?
a.
b.
c.

5. If you were going to know how to perform one research skill at the end of this course that you don't know how to do now, what would it be? 
6. What area of law are you hoping to practice?

7. On a scale of 1 (being least comfortable) to 10 (being most comfortable), how comfortable do you feel researching the following types of resources?
a. Binding case law
12234556788910
b. Statutes
123456788910
c. Regulations
12334567789910
d. Court Rules
12234556788910
e. Legislative History

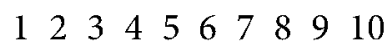
f. Forms
$\begin{array}{lllllllll}12 & 2 & 4 & 5 & 6 & 7 & 8 & 9 & 10\end{array}$
g. Secondary Sources
12345678910 